\title{
A Study of the Association between Helicobacter Pylori, on Steroidal Anti Inflammatory Drugs and Peptic Ulcer Disease
}

\author{
${ }^{1}$ Dr.S.Selvamani.MD, ${ }^{2}$ Dr.K.Sivakumar.MD, \\ ${ }^{1}$ Assistant professor, Department of General Medicine, Coimbatore Medical College \& Hospital. \\ ${ }^{2}$ Assistant professor, Department of General Medicine, Coimbatore Medical College \& Hospital.
}

\begin{abstract}
NASID induced gastro intestinal injury represent the most frequent adverse drug event worldwide. Despite the large number of drug used, the incidence of serious side effects due to NSAIDs is considerably low. The wide spectrum of side effects includes of those affecting renal, hepatic and haematological functions. The major gastrointestinal adverse effects include peptic ulcer disease, gastrointestinal bleeding and perforation. Peptic ulcer disease is a chronic inflammatory condition of the stomach and duodenum affecting approximately $15 \%$ of people the world over. The two causative factors are Helicobactor pylori and NSAID. Helicobacter pylori and NSAID are independent risk factors for the developments of gastroduodenopathy.The two factors together do not increase the risk of peptic ulcer disease. Asymptomatic individuals with normal endoscopy are associated with histological changes of gastritis. Antral ulcers are associated with low prevalence of HP. Predicting which patients taking chronic NSAID s are at risk of ulceration; bleeding or perforation needs further evaluation.
\end{abstract}

AIM OF THE STUDY:

\section{INTRODUCTION}
A. Identify the HP prevalence in chronic NSAID users
B. Determine the relation between HP infection and upper gastrointestinal symptoms in NSAID users.
C. Correlate endoscopic lesion and HP prevalence.
D. Identify the potentiating damaging effect of HP and NSAID on gastric mucosa.

\section{METHODOLOGY}

Between May 2014 and december 2014 a series of 100 patients suffering from rheumatoid arthritis (62) and osteoarthritis (20) and other musculoskeletal disorders who were on long term NSAID and irrespective of dyspeptic symptoms were included for a prospective study. The cases were selected from the Medical and Orthopaedic outpatient departments of Coimbatore Medical College Hospital.Patients who were receiving steroids and D-penicillamine were excluded from study.No patients were receiving $\mathrm{H} 2$ receptor antagonist or any other mucosal protective agents at the time of the of study.Chronic smokers and alcoholics are excluded from the study.

Control group consisted of age and sex matched patients with dyspeptic symptoms and were attending the Department of medical gastroenterology,Coimbatore Medical College Hospital,Coimbatore. None of the patients in the control group were on NSAID.

Details of arthritis, name and duration of NSAID used were noted. Patient's were subjected to thorough history taking and clinical examination; symptoms of frequency and severity of epigastric pain, noctural pain, nausea vomiting and heartburn were noted. A total upper gastrointestinal symptom score for each subject was calculated by combining the individual frequency and severity measure. Because frequency and severity grades are highly correlated for each subject, the frequency and severity of grades for a given gastro-intestinal symptom were multiplied and a total upper gastro-intestinal score was calculated as sum of cross products. Patients on NSAID and those not on NSAID (controls) had an upper gastro-intestinal endoscopy after an overnight fast and an informed consent. The gastro intestinal appearance was characterized using a modified scale proposed by Lanza et al. Endoscopy was considered as abnormal if the score was 1 and above. Two biopsy specimens were taken from the greater curvature of the antrum within $5 \mathrm{~cm}$ of the pylorus, one was intended for rapid urease and one for histological examination.

\section{RESULTS}

Patients taking NSAID and the control were similar in terms of age and sex ratio. There were 22 men (mean age: $37 \mathrm{yrs}$, range 28-53 yrs) and 78 women (mean age $44.8 \mathrm{yrs}$, range 15-70 yrs) who were on NSAID. 16 men and 36 women were positive for HP. Details of NSAID ingestion in these patients. 
Ibuprufen was the most frequent NSAID used either alone or in combination with indomethacin or diclofenac sodium (76/100), Diclofenac sodium alone was used by 10 patients; 2 patients ulcerative colitis and arthiritis was on Salazopyrin.

The mean duration of consumption of NSAID was 12 weeks.62 patients on NASID were symptom free.(frequency of HP infection was similar in the control group and in those taking NSAID(44\% Vs 52\% respectively)

1. Out of 44 patients with normal endoscopy and on NSAID, 26 were HP positive compared to 16 out of 42 in the control population. The odds ratio was 2.3. This indicates that patientd who take NSAID are at 2.3 times greater risk of having HP infection compared to those not on NSAID.

2. 56 patients on NSAID and 58 controls not on NSAID had abnormal endoscopic findings. 26 of the 56 NSAID patients were HP positive and 28 out of 58 patients with dyspepsia were HP positive. The odds ratio was 0.93 indicating that patients with abnormal endoscopy on NSAID are at 0.9 times at less risk of being HP positive than those who had an abnormal endoscopy without NSAID.

3.Ther were 36 asymptomatic NSAIDs users with abnormal endoscopy. 18 of whom were HP positive and 26 asymptomatic NSAID patients with normal endoscopy,12 of whom were HP positive.The odds ratio was 1.1 . This indicates that symptomatic patients who are HP patients who are HP positive are at 1.1 times greater risk of having endoscopic abnormalities compared to the patients who are HP negative.

4.When combined effect of HP and NSAIDs were considered to act synergistically and cause peptic ulcer disease the odds of developing peptic ulcer disease was considerably low in patients on NASID compared to controls on NSAID.An odds ratio of 0.9 indicates that patient positive for NSAID and HP are 0.9 times at lesser risk of having peptic ulcer disease compared to patients not on NSAID and negative for HP.

Histology was normal in $30(30 \%) ; 34(34 \%)$ had chronic gastritis,and 18 (18\%)each had chronic active gastritis and chemical gastritis.Helicobactor pylori was identified in $32(32 \%)$.

Endoscopic findings were correlated with histology and HP. Of 44 patients with normal endoscopy 28 had histological gastrtis (Chronic gastritis 18,Chronic active gastritis 6,Chemical gastritis 4 and HP was seen in 16 patients (36\%); 17 patients had mild to moderate endoscopic changes, 10 had chronic gastritis, 6 had chronic active gastritis and 12 chemical gastritis. Of the 22 patients with severe changes (antral ulcer-12) 8 had normal histology 6 had chronic gastritis, 6 chronic active gastritis and 2 chemical gastritis.

\section{SUMMARY}

1. There were 78 women, age range of $15-70$ and 22 men,age range $28-53$ years on long term NSAID for various musculoskeletal disorders'

2. The most common NSAID used was ibuprofen for mean duration of 12 weeks.

3. The frequency of HP was similar in the control group and in those taking NSAID (44\% vs 52\%) and $62 \%$ of NSAID users were asymptomatic.

4. Out of 62 symptomatic NSAID users, HP was positive in 30;amongst 38 symptomatic NSAID users, 22 were HP positive.

5. Endoscopy was normal in 44 patients (44\%), 34(34\%) had mild to moderate changes,22(22\%)had with severe changes which included 12 antral ulcers.Duodenal ulcer and erosion was seen in 8 patients.

6. Out of 44 patients with normal endoscopy, 28 had histological changes ,18 chronic gastritis ,6 chronic active gastritis and 4 chemical gastritis. Helicobacter was identified in 32 patients, 12 with normal histology 6 chronic gastritis , 8 chronic active gastritis and 6 chemical gastritis.

7. (a) Patients with normal endoscopy who were on NSAID are 2.3 times at a greater risk of having HP infection compared to those not on NSAID

(b) Patients with abnormal endoscopy and on NSAID were 0.9 times at a less risk of being HP positive than those who had an abnormal endoscopy without NSAID.

(c) In asymptomatic NSAID users those who were HP positive are at 1.1 times at a great risk of having endoscopic abnormalities than those who were HP negative.

(d) The odds od developing peptic ulcer diseasein NSAID users who were HP positive was low (0.9) compared to the controls not on NSAID but HP positive.

\section{CONCLUSION}

Helicobacter pylori and NSAID are independent risk factors for the developments of gastroduodenopathy. The two factors do not increase the risk of peptic ulcer disease. Asymptomatic individuals with normal endoscopy are associated with histological changes of gastritis. Antral ulcers are associated with low prevalence of HP 
Predicting which patients taking chronic NSAIDs are at risk of ulceration,bleeding or perforation needs further evaluation. Study on Helicobacter pylori in more number of cases is likely to provide better information and the true relationship between NSAID users,HP infection and peptic ulcer disease.

\section{REFERANCES}

[1]. Goggin PM, Collins DA,Jazrawi RP,et al. Prevalence of Helicobacter pylori infection and its effect on symptoms and non steroidal anti-inflammatory drug induced gastrointestinal damage in patients with rheumatoid arthritis.Gut 1993;34:1677-1680

[2]. Taha AS, Russel RL, Helicobacter pylori and non steroidal anti-inflammetory drugs-uncomfortable partners in peptic ulcer disease.Gut 1993;34:580-583.

[3]. Roth SH, Benett RE,NSAIDS and gastropathy: rheumatologists review.J.Rheumatoid 1998;15:912-8

[4]. Henry DA,Johnson A,Dobson A et al.Fatal peptic ulcer complications and the use of non steroidal anti inflammatory drugs,aspiring and corticosteroids.Br.Med J.1987,295:1227-9

[5]. 5.Brooks Pm,Yeomans Nd.Nonsteroidal anti-inflammatory drug gastropathy is it prevalence?Aust.NZ.Med.1992 ;22;685-991.

[6]. 6.Soll ah,Weinstein WM,Kurata $J$ et al.Non steroidal anti-inflammatory drugs and peptic ulcer disease Ann.Intern.Med,1991;114;307-319.

[7]. Griffin MR,Piper Jm,Daugherty JR, et al. On Steroidal anti-inflammatory drug use and increased risk for peptic ulcer disease in elderly persons.Ann inern Med 1991;114:257-263.

[8]. 8.Hamilton Sr, Yardley JH, Endoscopic biopsy of aspirin associated chronic gastric ulcers.Gastroenterology 1980;78;A.1178.

[9]. 9.Ballinger A.Prevention of peptic ulceration in patients receiving NSAID. Applied Medicine 1994;20.

[10]. 10.Borody Tj, Brandl S.Andrews P,et al, Helicobacter pylori negative gastric ulcer.Am.J.Gastroenterol.1992;87;1403-1406.

[11]. 11. The EUROGAST Study Group.Epidemiology of, and risk factors for, Helicobacter pylori infection among 3194 asymptomatic subjects in 17 populations.Gut $1993 ; 34: 1672-1676$.

[12]. 12. P.Sharma et al., Duodenal ulcer and H.pylori :Presidental oration. Dept.of Gastroenterology,AIIMS, Indian J.Gastroenterology,1999, April -June 78-83.

[13]. 13.Martin DF,Montgomery E,Dobek ,et al. Campylobacter pylori,non steroidal anti-inflammatory drugs and risk factors for peptic ulcer disease.Am.J.Gastroenterol,1989;84;1268-1272.

[14]. 14.Taha AS, Capell HA, Sturrock RD,et al. Non steroidal peptic damage in rheumatoid patients receiving second line drugs.Am.J.Gastroentrol 1999;86;1588-91.

[15]. 15.Caselli M,Pazzi P, La Corte et al,Campylobacter-like organisms, Non steroidal anti-inflammatory drugs and gastric lesions in patients with rheumatoid arthritis,Digestion,1989;44;101-4. 